\title{
Complications With Utilization of Positive-Pressure Devices in a Young Man With Duchenne Muscular Dystrophy
}

\author{
Scott L Gee RRT AE-C, Gary R Lowe MEd RRT-NPS RPFT, and Robert H Warren MD
}

\begin{abstract}
Because of the progressive muscle weakness they experience, patients with Duchenne muscular dystrophy frequently utilize positive-pressure devices to maintain adequate bronchial hygiene and ventilation. This case illustrates the course of a 19-y-old male who presented with a perforated right tympanic membrane (TM) following the use of these devices. Perforation of the TM while utilizing positivepressure devices is a rarely reported event. A challenging aspect in this case was balancing the reduction of pressures and maintaining adequate ventilation while at the same time allowing the TM to heal. Key words: positive-pressure ventilation; perforated tympanic membrane; myringorupture; insufflator-exsufflator; noninvasive ventilation. [Respir Care 2015;60(2):e30-e33. () 2015 Daedalus Enterprises]
\end{abstract}

\section{Introduction}

Because of the progressive muscle weakness that patients with degenerative neuromuscular diseases experience, positive-pressure devices are frequently utilized to maintain adequate bronchial hygiene and support ventilation. When used properly, these devices can improve quality of life and survival. ${ }^{1-5}$ In their review, Toussaint et al ${ }^{1}$ noted that patients with Duchenne muscular dystrophy (DMD) considered home mechanical ventilation to be beneficial for independent living and enhancing their overall health and quality of life, whereas health-related quality of life further decreased without mechanical ventilation. In their report, Kohler et $\mathrm{al}^{4}$ concluded that patients with DMD perceive a high health-related quality of life independent of the degree of their physical disability, respiratory impairment, and dependence on noninvasive ventila-

Mr Gee and Mr Lowe are affiliated with Respiratory Care Services, Arkansas Children's Hospital, Little Rock, Arkansas. Dr Warren is affiliated with the Pulmonary Medicine Section, Department of Pediatrics, University of Arkansas for Medical Sciences, Little Rock, Arkansas.

Mr Gee presented a version of this paper at the AARC Congress 2012, held November 10-13, 2012, in New Orleans, Louisiana.

The authors have disclosed no conflicts of interest.

Correspondence: Gary R Lowe MEd RRT-NPS RPFT, Respiratory Care Services, Slot 303, 1 Children's Way, Little Rock, AR 72202-3591. E-mail: lowegr@archildrens.org.

DOI: $10.4187 /$ respcare.03396 tion (NIV). Although quality of life is a good indicator for patients with DMD, a more important facet is the improvement in survival. Research performed by Ishikawa et $\mathrm{al}^{5}$ noted a significant increase in the 50\% survival age of patients using NIV and mechanically assisted cough devices (MACD) compared with those not using them. However, these devices can be responsible for unforeseen consequences that present unique challenges to the medical team. We describe a patient with DMD who experienced a perforated tympanic membrane (TM) during the course of his home-care regimen using positive-pressure devices.

\section{Case Report}

During a routine follow-up clinic visit with a pulmonologist, a 19-y-old male with DMD reported that while using an MACD at 35-40 $\mathrm{cm} \mathrm{H}_{2} \mathrm{O}$, he experienced a loud pop in his right ear. He also noted that while using NIV at night, he experienced a dull pain in his right ear and a whistling noise that kept him awake. The patient was unable to determine a specific time when the incident occurred but stated that it occurred within the last few weeks. The physical examination revealed him to be in no distress and resting comfortably in a chair. He was afebrile with a resting heart rate of 89 beats/min, a breathing frequency of 18 breaths/min, a blood pressure of 123/68 $\mathrm{mm} \mathrm{Hg}$, and an $\mathrm{S}_{\mathrm{pO}_{2}}$ of $97 \%$ on room air. Breath sounds were suppressed bilaterally, no crackles or wheezes were noted, and respiratory effort appeared unlabored. Heart auscultation revealed a regular rhythm without murmur. Examination of his head, eyes, nose, and throat revealed only some nasal 


\section{Complications With Positive-Pressure Devices in Duchenne Muscular Dystrophy}

Table 1. Timeline of Ventilator Changes Before and in Response to the Patient's Perforated TM and Subsequent CBG Results With Proceeding Increase in $\mathrm{P}_{\mathrm{CO}_{2}}$ Levels

\begin{tabular}{|c|c|c|c|c|c|c|c|c|c|c|c|c|c|}
\hline Time & Intervention & $\begin{array}{c}\text { Breathing } \\
\text { Frequency } \\
\text { (breaths/min) }\end{array}$ & $\begin{array}{c}\text { PIP } \\
\left(\mathrm{cm} \mathrm{H}_{2} \mathrm{O} \text { ) }\right.\end{array}$ & $\begin{array}{c}\text { PEEP } \\
\left(\mathrm{cm} \mathrm{H}_{2} \mathrm{O}\right)\end{array}$ & $\underset{\left(\mathrm{cm} \mathrm{H}{ }_{2} \mathrm{O}\right)}{\overline{\mathrm{a}}_{\mathrm{aw}}}$ & $\begin{array}{c}\text { Exhaled } \\
\mathrm{V}_{\mathrm{T}} \\
(\mathrm{mL} / \mathrm{kg})\end{array}$ & $\begin{array}{l}\mathrm{T}_{\mathrm{I}} \\
(\mathrm{s})\end{array}$ & $\begin{array}{l}\mathrm{P}_{\mathrm{ETCO}} \\
(\mathrm{mm} \mathrm{Hg})\end{array}$ & $\mathrm{pH}$ & $\underset{(\mathrm{mm} \mathrm{Hg})}{\mathrm{P}_{\mathrm{CO}_{2}}}$ & $\underset{(\mathrm{mmol} / \mathrm{L})}{\mathrm{HCO}_{3}^{-}}$ & $\begin{array}{l}\text { In-Exsufflator } \\
\left(\mathrm{cm} \mathrm{H}_{2} \mathrm{O}\right)\end{array}$ & TM Status \\
\hline$T-103 d$ & Clinic visit settings & 17 & 20 & 6 & 8 & 7 & 1.0 & 52 & 7.42 & 54 & 34.9 & $35 / 35$ & No air leak \\
\hline$T-103 d$ & $\begin{array}{l}\text { Clinic discharge } \\
\text { orders }\end{array}$ & 17 & 24 & 6 & & & 1.0 & & & & & $40 / 40$ & \\
\hline$T-96 d$ & $\begin{array}{l}\text { Telephone } \\
\text { intervention }\end{array}$ & 17 & 22 & 6 & & & 1.0 & & & & & $40 / 40$ & Not evaluated \\
\hline $\mathrm{T}=0 \mathrm{~d}$ & Clinic visit settings & 17 & 20 & 6 & 10 & 5 & 1.2 & 31 & 7.42 & 48.2 & 30.9 & $40 / 40$ & Perforated \\
\hline $\mathrm{T}=0 \mathrm{~d}$ & $\begin{array}{l}\text { Clinic discharge } \\
\text { orders }\end{array}$ & 17 & 16 & 6 & & & 1.4 & & & & & $30 / 30$ & \\
\hline$T+23 d$ & Clinic visit for $\mathrm{CBG}$ & & & & & & & & 7.38 & 54 & 32.5 & & Not evaluated \\
\hline$T+51 d$ & Clinic visit settings & 17 & 16 & 6 & 10 & 3 & 1.4 & 49 & 7.40 & 54 & 33.4 & $30 / 30$ & $\begin{array}{l}\text { Air leak reported } \\
\text { after clinic visit }\end{array}$ \\
\hline$T+143 d$ & Clinic visit settings & 17 & 20 & 6 & 11 & 5 & 1.4 & 55 & 7.40 & 58.9 & 36.3 & $30 / 30$ & Perforated \\
\hline $\mathrm{T}+205 \mathrm{~d}$ & Clinic visit settings & 17 & 20 & 6 & & & 1.4 & & 7.39 & 61.6 & 36.9 & $30 / 30$ & Perforated \\
\hline$T+268 d$ & Clinic visit settings & 17 & 22 & 5 & 10 & 5 & 1.0 & 59 & 7.37 & 65.2 & 37.7 & $30 / 30$ & No air leak \\
\hline$T+268 d$ & $\begin{array}{l}\text { Clinic discharge } \\
\text { orders }\end{array}$ & 17 & 25 & 5 & & 7 & 1.2 & & & & & & \\
\hline $\begin{array}{l}\mathrm{PIP}=\text { peak } \\
\overline{\mathrm{P}}_{\mathrm{aw}}=\text { mean } \\
\mathrm{V}_{\mathrm{T}}=\text { tidal } \mathrm{v} \\
\mathrm{T}_{\mathrm{I}}=\text { inspirat } \\
\mathrm{P}_{\mathrm{ETCO}_{2}=\text { en }} \\
\text { In-Exsufflatc } \\
\mathrm{TM}=\text { tymp } \\
\mathrm{T}=\text { time } \\
\mathrm{CBG}=\text { capi }\end{array}$ & $\begin{array}{l}\text { inspiratory pressure } \\
\text { airway pressure } \\
\text { olume } \\
\text { tory time } \\
\text { d-tidal carbon dioxide pre } \\
\text { or = insufflator-exsufflator } \\
\text { anic membrane } \\
\text { llary blood gas }\end{array}$ & ssure & & & & & & & & & & & \\
\hline
\end{tabular}

turbinate edema with minimal drainage. The extremities were negative for clubbing or edema. Capillary refill was brisk, and nail beds were pink. He was negative for any significant scoliosis or kyphosis. Capillary blood gas (CBG) revealed a $\mathrm{pH}$ of $7.42, \mathrm{P}_{\mathrm{CO}_{2}}$ of $48.2 \mathrm{~mm} \mathrm{Hg}, \mathrm{HCO}_{3}{ }^{-}$at $30.9 \mathrm{mmol} / \mathrm{L}$, and a base excess of $6 \mathrm{mmol} / \mathrm{L}$ (Table 1 ).

The respiratory home-care regimen to maintain cardiopulmonary stability included supplemental oxygen used only as needed, a pulse oximeter to monitor $\mathrm{S}_{\mathrm{pO}_{2}}$ levels, a home-care ventilator (LTV 950, Pulmonetic Systems, Colton, California) used during sleep, a suction machine to assist in clearing airway secretions, and an MACD (Emerson CoughAssist mechanical insufflator-exsufflator, Philips Respironics, Murrysville, Pennsylvania) for lung expansion exercises and to assist ineffective and weak cough.

To further investigate the right ear complaint, the patient was placed on NIV for assessment. His home-care ventilator was used with his home regimen settings: assist control/pressure control mode, breathing frequency of 17 breaths/min, pressure control of $20 \mathrm{~cm} \mathrm{H}_{2} \mathrm{O}$, PEEP of $6 \mathrm{~cm} \mathrm{H}_{2} \mathrm{O}$, and inspiratory time of $1.2 \mathrm{~s}$. A full face mask (PerformaTrak, Philips Respironics) was used. These settings resulted in an expired tidal volume of $5 \mathrm{~mL} / \mathrm{kg}$ (total volume of $410 \mathrm{~mL}$ ) and a mean airway pressure of $10 \mathrm{~cm} \mathrm{H}_{2} \mathrm{O}$. Following placement on the ventilator, repeat CBG was obtained with a reduction in $\mathrm{P}_{\mathrm{CO}_{2}}$ from 48 to $43 \mathrm{~mm} \mathrm{Hg}$, whereas the $\mathrm{pH}$ and $\mathrm{HCO}_{3}{ }^{-}$remained essentially unchanged. During this evaluation, with a pressure

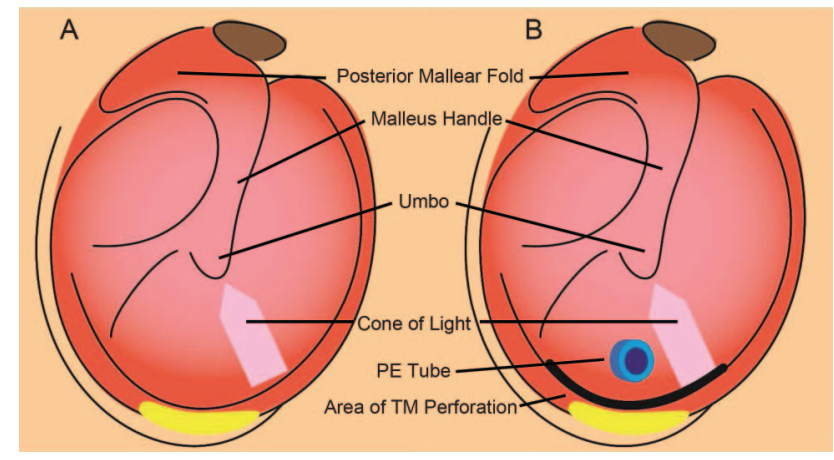

Fig. 1. A: Illustration depicting a normal tympanic membrane (TM). B: Illustration depicting the perforation at the base of the TM upon visual examination of the ear during the initial clinic visit. The perforation caused the TM to flutter during positive-pressure ventilation.

control of $20 \mathrm{~cm} \mathrm{H}_{2} \mathrm{O}$, air could be heard escaping from the right ear. During visual examination, the TM was noted to be moving in a flutter-like presentation. He had a pressure equalization (PE) tube in place that could be visualized (Fig. 1). It was clear that air was escaping through a perforation at the base of the right TM. The left TM was noted to be normal. According to the caregiver, the patient had bilateral PE tubes placed when he was a baby, but a specific timeline could not be established. In an attempt to minimize the air flow through the TM, pressure control was reduced from 20 to $18 \mathrm{~cm} \mathrm{H}_{2} \mathrm{O}$. The patient felt that the ventilator was giving him an appropriate volume. The 


\section{Complications With Positive-Pressure Devices in Duchenne Muscular Dystrophy}

fluctuations of the right TM could still be appreciated, and he felt discomfort in the right ear. Pressure control was further reduced to $16 \mathrm{~cm} \mathrm{H}_{2} \mathrm{O}$, and he became asymptomatic with regard to any ear problems.

The patient was discharged from the out-patient clinic on the following ventilator settings: breathing frequency of 17 breaths/min, pressure control of $16 \mathrm{~cm} \mathrm{H}_{2} \mathrm{O}$, PEEP of $6 \mathrm{~cm} \mathrm{H}_{2} \mathrm{O}$, and inspiratory time of $1.2 \mathrm{~s}$. MACD pressures were also lowered to a maximal setting of $30 \mathrm{~cm} \mathrm{H}_{2} \mathrm{O}$, a reduction from his previous home-care regimen of 35$40 \mathrm{~cm} \mathrm{H}_{2} \mathrm{O}$. An appointment was made with an ear, nose, and throat (ENT) specialist for evaluation and to determine a strategy for correction of the right TM perforation.

Three days after the initial clinic visit, the ENT specialist removed the PE tube. No other interventions were performed. It was expected the TM would heal in time. After several days, the patient still noted air escaping from his right ear. There was concern that the positive-pressure devices would not allow the perforation to heal, even with the reduction of pressures. To address this concern, the patient was to remain off NIV for the following $3 \mathrm{~d}$ and to use only the MACD as needed and not on a regular basis. The patient's $\mathrm{S}_{\mathrm{pO}_{2}}$ was closely monitored during this time period. A follow-up appointment was made with the ENT specialist 1 month after the removal of the PE tube.

Seventeen days after the initial clinic visit, the patient reported using NIV 3 times per week. He also stated that he did not hear air leaking though his ear, and he had no complaint of ear pain or discomfort. He used the MACD once daily to relieve congestion. He was instructed to continue the current regimen and to get a repeat CBG the following week. Additionally, no changes in pressures or frequency of use were to be initiated until the CBG results were obtained and the status of the TM could be assessed by the ENT specialist. Twenty-three days after the initial clinic visit, $\mathrm{CBG}$ revealed a $\mathrm{pH}$ of $7.38, \mathrm{P}_{\mathrm{CO}_{2}}$ of $54.0 \mathrm{~mm} \mathrm{Hg}$, $\mathrm{HCO}_{3}{ }^{-}$at $32.5 \mathrm{mmol} / \mathrm{L}$, and a base excess of $7 \mathrm{mmol} / \mathrm{L}$. One month after the initial clinic visit, the ENT specialist stated that the TM had completely healed and that changes in pressures and frequency of use of NIV and the MACD could be considered. It was decided that no changes would be made until the patient could be seen in the clinic by the pulmonologist 2 weeks later.

The patient was seen for a follow-up clinic visit $51 \mathrm{~d}$ after the initial clinic visit. Pressure control during NIV was increased from 16 to $20 \mathrm{~cm} \mathrm{H}_{2} \mathrm{O}$. CBG revealed a $\mathrm{pH}$ of $7.4, \mathrm{P}_{\mathrm{CO}_{2}}$ of $54 \mathrm{~mm} \mathrm{Hg}, \mathrm{HCO}_{3}{ }^{-}$at $33.4 \mathrm{mmol} / \mathrm{L}$, and a base excess of $9 \mathrm{mmol} / \mathrm{L}$. He was to increase his use of NIV to every night and to continue with the MACD at pressures of $30 / 30 \mathrm{~cm} \mathrm{H}_{2} \mathrm{O}$. Approximately 1 week later, he was tolerating the increased pressure with NIV. However, he had increased sinus drainage and increased coughing. He required the MACD 3 times daily to mobilize secretions and noted that, after these sessions, his ear made bubbling noises. It was recommended he be evaluated by the ENT specialist again and, if possible, to have his ear examined while the ventilator was in use.

Five months after the initial clinic visit, the patient was seen by the pulmonologist. NIV settings were: assist control/pressure control mode, breathing frequency of 17 breaths/min, pressure control of $20 \mathrm{~cm} \mathrm{H}_{2} \mathrm{O}$, PEEP of $6 \mathrm{~cm} \mathrm{H}_{2} \mathrm{O}$, and inspiratory time of $1.4 \mathrm{~s}$. These settings resulted in an expired tidal volume of $5 \mathrm{~mL} / \mathrm{kg}$ (total volume of $425 \mathrm{~mL}$ ) and a mean airway pressure of $11 \mathrm{~cm} \mathrm{H}_{2} \mathrm{O}$. $\mathrm{CBG}$ revealed a $\mathrm{pH}$ of $7.4, \mathrm{P}_{\mathrm{CO}_{2}}$ of $58.9 \mathrm{~mm} \mathrm{Hg}, \mathrm{HCO}_{3}{ }^{-}$ at $36.3 \mathrm{mmol} / \mathrm{L}$, and a base excess of $11 \mathrm{mmol} / \mathrm{L}$. It was noted that the TM was still leaking. No changes were made, and the patient was to return to the clinic 2 months later. At that clinic visit, no changes were noted in NIV or MACD settings, and a repeat $\mathrm{CBG}$ revealed a $\mathrm{pH}$ of 7.39, $\mathrm{P}_{\mathrm{CO}_{2}}$ of $61.6 \mathrm{~mm} \mathrm{Hg}, \mathrm{HCO}_{3}{ }^{-}$at $36.9 \mathrm{mmol} / \mathrm{L}$, and a base excess of $12 \mathrm{mmol} / \mathrm{L}$. He was also seen by the ENT specialist at that time. His TM was still leaking air, but the ENT specialist was optimistic that it would heal.

Eight months after the initial clinic visit, the patient collapsed at work. He was noted by co-workers to be cyanotic, with no pulse or respiration. Cardiopulmonary resuscitation was performed, and he became awake and alert. He was taken to the local emergency department and examined. Chest x-ray, electrocardiogram, and blood gas were obtained, and all were within normal limits. It was suggested that the patient be admitted for observation, but he refused. He was subsequently discharged from the emergency department. Approximately 9 months after the initial report of TM perforation, he was again seen by the pulmonologist. At this point, it was determined that the TM was no longer leaking. Pressure control during NIV was increased from 22 to $25 \mathrm{~cm} \mathrm{H}_{2} \mathrm{O}$, resulting in an exhaled tidal volume of $7 \mathrm{~mL} / \mathrm{kg}$ (total volume of $600 \mathrm{~mL}$ ) in an attempt to improve his ventilatory status and to normalize $\mathrm{P}_{\mathrm{CO}_{2}}$ levels. He was lost to follow-up, and confirmation of improving $\mathrm{P}_{\mathrm{CO}_{2}}$ levels was not verified.

\section{Discussion}

Perforated TM associated with positive-pressure ventilation has rarely been reported in the medical literature. A literature search in PubMed utilizing the search terms positive-pressure ventilation, perforated TM, myringorupture, insufflator-exsufflator, and NIV in various combinations revealed only one reported occurrence. ${ }^{6}$ Studies to determine the pressures needed to perforate TMs have been carried out on subjects postmortem. One study noted that pressures required to perforate TMs ranged from 984 to 2,320 $\mathrm{cm} \mathrm{H}_{2} \mathrm{O}$ (mean of $1,758 \mathrm{~cm} \mathrm{H}_{2} \mathrm{O}$ ) on 30 cadaver TMs, with the observations made between 2 and $14.5 \mathrm{~h}$ postmortem. ${ }^{7}$ Another study of cadaver subjects with normal TMs $(n=144)$ noted that perforation pressures ranged 


\section{Complications With Positive-Pressure Devices in Duchenne Muscular Dystrophy}

from 700 to 2,300 $\mathrm{cm} \mathrm{H}_{2} \mathrm{O}$ (median of $1,300 \mathrm{~cm} \mathrm{H}_{2} \mathrm{O}$ ), while for TMs with atrophic scars $(n=23)$, perforation pressures ranged from 300 to $800 \mathrm{~cm} \mathrm{H}_{2} \mathrm{O}$ (median of $600 \mathrm{~cm} \mathrm{H}_{2} \mathrm{O}$ ), with the observations made between 7 and $112 \mathrm{~h}$ postmortem. ${ }^{8}$ Another study on blast injuries noted that auditory injury happened at the lowest blast overpressure of $357 \mathrm{~cm} \mathrm{H}_{2} \mathrm{O} .{ }^{9}$ This is in close agreement with the pressures noted in perforating TMs with atrophic scars.

In this patient, there was no documentation of any type of TM injury that would have contributed to the perforation. Additionally, the PE tube should have served as a pressure relief device to prevent TM perforation. This did not occur. The opening in the TM made by the insertion of the PE tube could actually increase the risk of a perforation-type injury due to atrophic scarring, as noted in the study by Jensen and Bonding. ${ }^{8}$ The patient's PE tube should have allowed elevated pressure to be released. If the PE tube was occluded, the TM possibly perforated as a result of the increased pressure applied by the MACD. This would have occurred at a lower pressure than a normal TM. However, the pressure applied by the MACD at $40 \mathrm{~cm} \mathrm{H}_{2} \mathrm{O}$ was only $7 \%$ of that reported for the lowest pressure observed for TM perforation in TMs with atrophic scarring.

The American Association for Respiratory Care clinical practice guideline on use of positive-pressure adjuncts to bronchial hygiene therapy lists "known or suspected TM rupture or other middle ear pathology" as a contraindication to this mode of treatment. ${ }^{10}$ However, the authors found no evidence of TM rupture or perforation noted as a hazard or complication resulting from utilization of positive-pressure devices in any other clinical practice guidelines. This would attest to the rarity of this event occurring. There are many respiratory devices that generate positive pressure; however, the pressures utilized are a fraction of what is required to rupture a TM based on the above studies. This may explain the scarcity of information in the medical literature.

It is possible that the combination of a compromised TM, an occluded PE tube, pressures generated by the MACD, and the patient performing a Valsalva maneuver simultaneously may have led to a significant increase in pressure and resulted in TM perforation. Another possibility is the uncertainty of the patient's actual compliance with the home-care regimen. During periods of time when he was not experiencing respiratory difficulties, we suspect that overall compliance was quite low. When he started to experience increased mucous production and dyspneic episodes, we suspect that he complied with the home-care regimen to avert possible deterioration resulting in hospitalization. Restarting his home-care regimen in an aggressive fashion may have caused the TM perforation. These potential explanations are speculative: however, some combination of these factors probably contributed to the perforated TM.
In this case, the importance of duplicating the homecare regimen in the clinic to validate the patient's complaints was invaluable. Clinicians were able to modify the pressures and minimize the air flow through the TM while directly visualizing the TM and getting direct input from the patient. Without visual confirmation of the perforated TM during NIV, downward adjustments in pressures during NIV and using the MACD might not have been performed. Although substantial efforts were made to minimize pressures, the TM would appear to heal and then subsequently start leaking air again. This continued over an extensive period of time (9 months) and led to an increase in $\mathrm{P}_{\mathrm{CO}_{2}}$ levels.

This case illustrates the following points. First, pressures utilized during NIV and with the MACD had to be reduced to allow the TM to heal. Second, following the reduction of pressures during NIV and with the MACD, there was a resultant increase in capillary $\mathrm{P}_{\mathrm{CO}_{2}}$ levels during the timeframe reviewed. Third, the patient's lack of compliance regarding the medical regimen led to a resuscitation event that was successfully managed. The TM eventually healed, and measures were subsequently initiated to increase pressures during NIV and with the MACD in an attempt to normalize the $\mathrm{P}_{\mathrm{CO}_{2}}$ levels. This rare presentation created many challenges for the medical team.

\section{ACKNOWLEDGMENTS}

We thank Mr Michael Spigner (Public Relations Department, Arkansas Children's Hospital) for creating the illustration used in this manuscript.

\section{REFERENCES}

1. Toussaint M, Chatwin M, Soudon P. Mechanical ventilation in Duchenne patients with chronic respiratory insufficiency: clinical implications of 20 years of published experience. Chron Respir Dis 2007; 4(3):167-177.

2. Ali S, Kabir Z. Domiciliary non-invasive ventilation and the quality of life outcome of patients suffering from chronic respiratory failure. Ir Med J 2007;100(1):336-338.

3. Finsterer J. Cardiopulmonary support in Duchenne muscular dystrophy. Lung 2006;184(4):205-215.

4. Kohler M, Clarenbach CF, Böni L, Brack T, Russi EW, Bloch KE. Quality of life, physical disability, and respiratory impairment in Duchenne muscular dystrophy. Am J Respir Crit Care Med 2005; 172(8):1032-1036.

5. Ishikawa Y, Miura T, Ishikawa Y, Aoyagi T, Ogata H, Hamada S, Minami R. Duchenne muscular dystrophy: survival by cardio-respiratory interventions. Neuromuscul Disord 2011;21(1):47-51.

6. Weaver LK, Fairfax WR, Greenway L. Bilateral otorrhagia associated with continuous positive airway pressure. Chest 1988;93(4):878-879.

7. Keller AP Jr. A study of the relationship of air pressure to myringorupture. Laryngoscope 1958;68(12):2015-2029.

8. Jensen JH, Bonding P. Experimental pressure induced rupture of the tympanic membrane in man. Acta Otolaryngol 1993;113(1):62-67.

9. Wolf SJ, Bebarta VS, Bonnett CJ, Pons PT, Cantrill SV. Blast injuries. Lancet 2009;374(9687):405-415.

10. AARC clinical practice guideline. Use of positive airway pressure adjuncts to bronchial hygiene therapy. American Association for Respiratory Care. Respir Care 1993;38(5):516-521. 